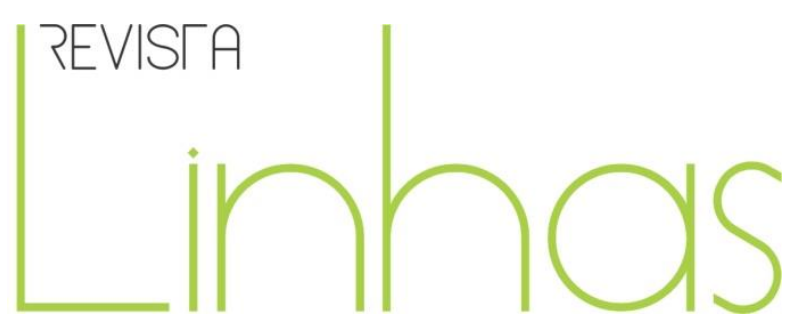

\title{
Ler livros sem palavras, ler imagens e mundos
}

\section{Resumo}

A escola que objetiva a formação do leitor literário deve ter como princípio o ensino de literatura, especialmente, através de leituras prazerosas em que o aluno sinta-se motivado a ler. A leitura prazerosa não exclui o processo de aquisição do conhecimento, pelo contrário, o leitor é estimulado à curiosidade e absorve novas informações, construindo assim novos conhecimentos. É importante que a escola priorize a diversidade e a qualidade do material que as crianças vão utilizar e que as metodologias adotadas pelos professores mediadores do conhecimento da leitura literária sejam variadas e propositivas ao pensamento, à imaginação e à criatividade. Neste caso, a literatura infantil oferece ao leitor a diversidade cultural, social e estética que ele, possivelmente, ainda não conhece, ampliando seu horizonte no encontro com o universo da ficção, da fantasia, do imaginário e de sua própria identidade, cercado de informações e características de uma determinada cultura. Sendo assim, abordamos nesse artigo questões a respeito da leitura literária nos anos iniciais, do ensino fundamental, a partir da perspectiva da educação literária, da alfabetização e do letramento literário, tendo como centro a leitura de livros de imagens ou livros de ilustração. $\mathrm{O}$ objetivo é apresentar discussões a respeito da formação do leitor e a presença da literatura infantil no processo de alfabetização e letramento, bem como mostrar a importância dos livros de imagens/ilustração na sala de aula dos anos iniciais e suas possíveis abordagens teórico-metodológicas.

Palavras-chave: Literatura Infantojuvenil. Leitura. Livros de Imagem.

\section{Daniela Segabinazi}

Universidade Federal da Paraíba - UFPb - Brasil

dani.segabinazi@gmail.com

\section{Para citar este artigo:}

SEGABINAZI, Daniela. Ler livros sem palavras, ler imagens e mundos. Revista Linhas. Florianópolis, v. 18, n. 37, p. 22-45, maio/ago. 2017. 


\title{
Read wordless books, read images and worlds
}

\begin{abstract}
The school that aims at the formation of the literary reader should have the teaching of literature as principle, especially through pleasant readings in which the student feels motivated to read. Pleasant reading does not exclude the process of acquiring knowledge, on the contrary, the reader is stimulated to curiosity and absorbs new information, thus building new knowledge. It is important that the school prioritize the diversity and quality of the material that children will use and that the methodologies adopted by the teachers mediating the knowledge of literary reading are varied and provocative to the thought, the imagination and the creativity. In this case, children's literature offers to the reader the cultural, social and aesthetic diversity that it, possibly, does not yet know, therefore expanding its horizon in the encounter with the universe of fiction, fantasy, imaginary and its own identity, surrounded by information and characteristics of a given culture. Thus, we approach, in this article, questions about literary reading in the initial years of elementary school, from the perspective of literary education, literacy and literary literacy, centered on the reading of picture books or illustration books. The objectives are to present discussions about the training of the reader and the presence of children's literature in the process of literacy and alphabetization, as well as to show the importance of the picture / illustration books in the classroom of the initial years, together with the possible theoreticalmethodological approaches.
\end{abstract}

Keywords: Children's Literature. Reading. Picture Books. 


\section{Primeiras leituras, primeiras escritas}

Todas as turmas do primeiro ano da "alfabetização" chegam ávidas e sedentas para "aprender a ler e escrever". Na turma da professora Rosa Suzana', em 2012, não foi diferente. Mas a proposta da professora para começar aquele ano é que foi incomum, dando início às primeiras leituras e primeiras escritas com a tarefa de ler e escrever a história O telefone, exposta na obra A bruxinha atrapalhada (2004), de Eva Furnari; e, os resultados dessa atividade diagnóstica são alguns dos exemplos a seguir:

(Fig. 1 - Atividade A1)
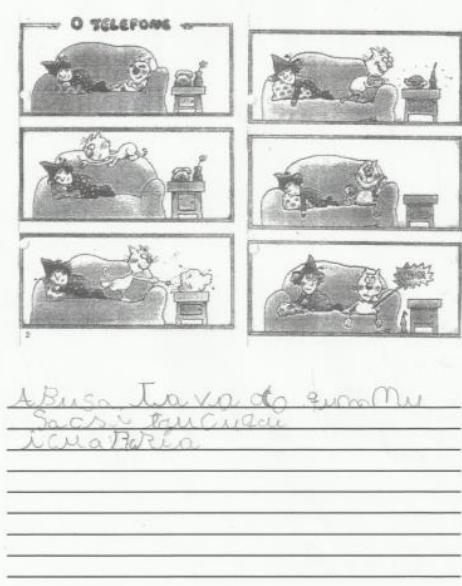

(Fig. 2 - Atividade A5)
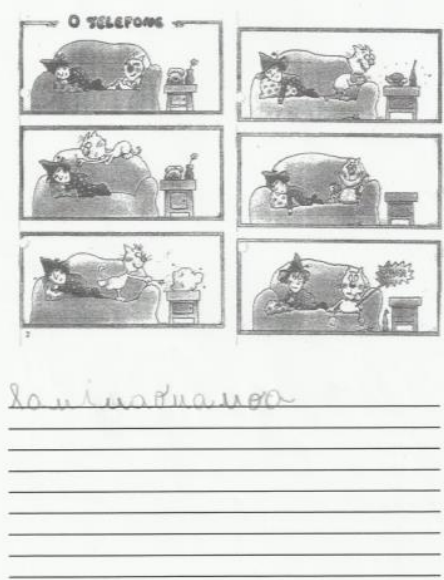

(Fig. 3 - Atividade A10)
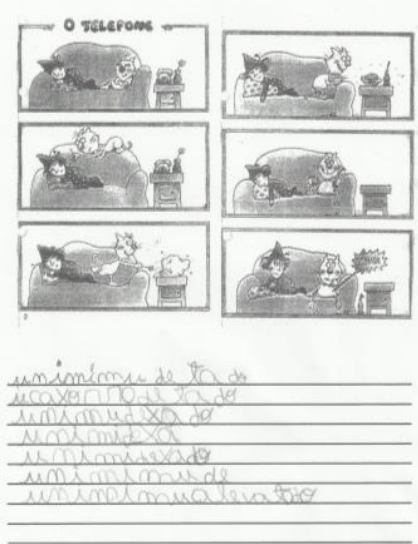

Fonte: BRITO (2013, p. 107-121)

As atividades realizadas por esses três alunos ( $A_{1}, A_{5}$ e $\left.A 10\right)$ apontam diferentes percursos da aquisição do código escrito, evidenciando o que os estudos de Emilia Ferreiro e Ana Teberosky (2011) apontavam sobre as ideias infantis que as crianças têm sobre a escrita. Neste caso, todos os exemplos mostram que as crianças percebem a diferenciação entre letras e números, bem como ultrapassaram o estágio do grafismo primitivo, portanto, em nível de escrita silábica, silábica-alfabética e da escrita sem controle de quantidade de letras, portanto, desordenada (Fig. 3).

Completando o diagnóstico, também foi possível saber como os mesmos alunos realizaram a leitura das imagens que compõem a história $O$ telefone, de Eva Furnari. De

\footnotetext{
${ }^{1}$ Dados retirados do Trabalho de Conclusão de Curso de Rosa Suzana Alves de Brito; ver em referências.
} 
acordo com o registro da professora, apresentado no Quadro 1, cada aluno leu da seguinte maneira:

Quadro 1- Atividade avaliativa diagnóstica de leitura e escrita

\begin{tabular}{|c|l|l|}
\hline Sujeito & \multicolumn{1}{|c|}{ Leitura } & \multicolumn{1}{|c|}{ Escrita } \\
\hline A1 & $\begin{array}{l}\text { Conseguiu contar a história em uma } \\
\text { sequência lógica e identificou os } \\
\text { personagens e os objetos das } \\
\text { imagens. }\end{array}$ & $\begin{array}{l}\text { Escreveu: } \\
\text { buSatavaddoqumnuSacsitaucuquicuaRaRia } \\
\text { - leu: A bruxa estava dormindo comendo } \\
\text { sanduíche tomando o suco encheu a barriga. }\end{array}$ \\
\hline A5 & $\begin{array}{l}\text { Conseguiu contar a história em uma } \\
\text { sequência lógica e identificou os } \\
\text { personagens e objetos das imagens. }\end{array}$ & $\begin{array}{l}\text { Escreveu: lauiuaouauoa - leu: estava } \\
\text { dormindo com o gato. O gato fez } \\
\text { desaparece o telefone e comeu tudo, ela se } \\
\text { acordou e ele se fez de santinho para ela } \\
\text { não brigar com ele. }\end{array}$ \\
\hline \multirow{5}{*}{ A10 } & $\begin{array}{l}\text { Não conseguiu contar a história em } \\
\text { uma sequência lógica, disse apenas } \\
\text { frases soltas para cada imagem; só } \\
\text { identificou um dos personagens e } \\
\text { alguns objetos das imagens. }\end{array}$ & $\begin{array}{l}\text { Escreveu: unimimudetado. } \\
\text { U caxorrodetado. } \\
\text { U nimudexado. } \\
\text { U nimidexa. } \\
\text { Unimidexado. } \\
\text { U nimimude. } \\
\text { U nimimualevatado. - leu: } \\
\text { O menino e o cachorro deitado. } \\
\text { O menino deitado e o cachorro sentado. } \\
\text { O menino dormindo e o cachorro em pé. } \\
\text { O menino dormindo e o cachorro em pé } \\
\text { também. }\end{array}$ \\
\hline
\end{tabular}

Fonte: BRITO (2013, p. 57-58)

As análises e transcrições da leitura e da escrita dos alunos corroboram a assertiva de que as crianças também têm ideias sobre a leitura. Todavia, muitos estudos ainda confirmam as ideias associadas à leitura a partir da escrita, isto é, apresentam a aquisição da leitura a partir do texto verbal, da codificação dos sons da fala e da decodificação dos sinais gráficos. Inclusive, essa concepção tem guiado o principal objetivo do primeiro ano, dos Anos Iniciais, quando não da Educação Infantil, porque "acreditava-se que a criança não podia ler antes que soubesse ler: não podia 'ler de verdade' antes que fosse capaz de 
'decodificar' a língua escrita, aprendida em 'textos' construídos não para ler, mas para ensinar a ler" (SOARES, grifos do autor, 2010, , p. 14).

No entanto, no final dos anos 80 (Século XX), vislumbra-se, com a chegada das teorias sociocognitiva e sociocultural da aprendizagem, a transformação dos conceitos e métodos de alfabetização na escola brasileira. Certamente, são essas mudanças que permitiram à professora Rosa Suzana preparar um novo começo de ano para sua turma e introduzir a leitura de livros de literatura como prática do letramento literário e da alfabetização dos seus alunos. Outrossim, ao fazer alusão às práticas renovadoras a partir desse contexto, queremos realçar a significativa contribuição que a literatura infantil tem oferecido na formação de leitores, particularmente, nos anos iniciais do ensino fundamental.

Assim, ao introduzirmos as primeiras leituras e as primeiras escritas dessas crianças, também começamos nossas primeiras provocações para ler livros sem palavras, ler imagens e mundos. A propósito, diz Graça Ramos:

Nem todo o livro de imagens é construído a partir de um roteiro ou de uma história já conhecida. Quando se depara com um livro-imagem cuja narrativa é inédita, o leitor se torna responsável por criar o texto verbal. As crianças, pouco compromissadas com a lógica, são capazes de dar diferentes rumos para uma história proposta a partir dessa linguagem em que as palavras estão ausentes. (RAMOS, 2013, p. 109)

E, para nos aproximar dessas discussões, nosso roteiro continua com a abordagem sobre a leitura dos livros de imagem e/ou livros ilustrados e sua importância para o letramento literário na alfabetização, acercando-se das concepções de estratégias de leitura; para, posteriormente, apresentar experiências e propostas de leituras nos anos iniciais a fim de contribuir com o alargamento de possibilidades metodológicas para alfabetizar letrando através da educação literária. 


\section{1. "Por favor, por favor, por favor, por favor, escolha um livro com figuras"²}

Implorando um livro com figuras, o narrador de O livro sem figuras, de B. J. Novak (2015), dá vigor e intensidade às criações literárias que elegem o gênero livro ilustrado como produto estético. Ademais, acentua que ler não recai tão somente em leitura de palavras. Consequentemente, alerta o leitor para o olhar mais sensível e mais aguçado, em busca de sentidos e sensações que as ilustrações oferecem; experiências que não se traduzem apenas na descrição das imagens, mas despertam para a construção de significados percebidos pelos detalhes, movimentos, cores, técnicas, texturas, estilos, expressões e etc.

Nesse sentido, vale lembrar as funções atribuídas às imagens que o escritor e ilustrador Luis Camargo (1995) descreveu em sua obra Ilustração do livro infantil. São funções que se entrelaçam para oportunizar a leitura e interpretação dos textos visuais e também verbo-visuais, demandando do leitor mais que mera observação; é uma participação ativa que propõe o jogo da descoberta entre leitor/criança e imagem, que vai da percepção de detalhes à imaginação e criação de fatos propiciados por funções denominadas de narrativa, expressiva/ética, simbólica, lúdica e estética, entre outras, e, que "tende a ser traduzida e significada por meio da palavra" (PAIVA; RAMOS, 2016, p. 215). Ou seja, o ponto de partida é a leitura de livros sem palavras, mas o ponto de chegada é ler imagens e mundos verbalizados pela palavra, seja na contação oral e/ou no registro escrito de uma história. Por esse ângulo, as autoras Paiva e Ramos (2016, p. 21516) consideram que:

\footnotetext{
${ }^{2}$ NOVAK, B. J., 2015, s/p.
} 
Assim, a compreensão pode ser "o processo de questionamento recíproco de um capital gráfico diante dos olhos e de um capital semântico atrás dos olhos" (FOUCAMBERT, 1998, p. 120). Nesse campo cognitivo, compreender implica uma ação/reação do leitor diante do texto que se dá pela interação; neste caso, tratamos do texto que opera só com imagens. Em síntese, as ilustrações são textos que convidam, conduzem e provocam o leitor a sentir, perceber e pensar para expressar, narrar, dizer e traduzir a imensidão que vai além do visível e notório, portanto, "nada em uma ilustração é gratuito. Isso significa que o leitor curioso poderá correlacionar as ilustrações com uma série de temas e outras expressões artísticas" (RAMOS, 2013, p. 102).

É preciso reconhecer, então, que os livros de imagem convertem-se em livros que podem ser traduzidos em palavras quando aceitos como fonte de pensamento que organizam o mundo das crianças ou quando instigam ao preenchimento de vazios que as levam a tomada de consciência do que sabem. Aliás, mesmo Peter Hunt (2010, p. 247), que afirma simpatizar com a noção de que o livro-imagem priva as crianças das palavras, acredita na potencialidade da ausência de palavras, que, de acordo com o autor "às vezes (...) pode fornecer um 'hiato' que necessita da inteligência e da imaginação para ser preenchido".

Em termos educacionais, pesquisadores e teóricos reafirmam a importância da literatura infantil na alfabetização. Magda Soares, no artigo Alfabetização e literatura (2010), publicado na Revista Educação (em comemoração aos 20 anos do CEALE), defende a relação entre alfabetização e literatura ao asseverar que a prática da leitura literária não só possibilita às crianças uma alternativa de lazer e prazer, mas também torna o mundo e a vida compreensíveis para elas, além de permitir o desenvolvimento e habilidades de compreensão, interpretação e construção de sentidos, relacionadas ao universo textual. Também Juracy A. Saraiva (2001), ao escrever seu livro Literatura e Alfabetização, ratifica a aproximação entre esses conhecimentos, trazendo à tona fundamentos sociopsicolinguísticos e psicogenéticos da alfabetização em consonância com teorias que abordam a leitura literária, a natureza e a função da literatura. A autora acredita que: 
Por desenvolver as áreas afetiva e intelectual, a leitura de textos literários, na fase da alfabetização, oferece às crianças a oportunidade de se apoderarem da linguagem, uma vez que a expressão do imaginário as liberta das angústias próprias do crescimento e lhes proporciona meios para compreender o real e atuar criativa e criticamente sobre ele. Consequentemente, os textos literários transcendem o estatuto de meio ou de instrumento hábil a facilitar o processo de alfabetização, para se afirmarem como elemento essencial, capaz de harmonizar a relação sujeito-mundo, oferecendo àquele outra via de reflexão. (SARAIVA, 2001, p. 83)

Não obstante, as autoras não incluam em suas abordagens o livro-imagem, ainda assim, colaboram para valorizar a presença da literatura infantil no ciclo da alfabetização. Ambas apresentam discussões, análises de obras e metodologias que auxiliam na aquisição da cultura escrita, porém, sem ignorar a potência formativa do texto literário infantil. Desse modo, os livros de imagem conciliam propostas que sugerem práticas escolares de letramento literário em conjunto com atividades de aquisição da língua escrita e leitura.

Nessa perspectiva, seria muito comum a manipulação de livros de imagem para "ler/contar" a narrativa percebida pelo olhar da criança; aliás, essa é uma das primeiras funções da ilustração. Entretanto, nem sempre os professores conduzem essa leitura na sala de aula; ignoram a presença diária de imagens e histórias no entorno das crianças e partem diretamente para exercícios de escrita e leitura de textos artificiais, preparados para alfabetizar. Nesses casos, presumimos que, em sua qualificação docente, não tiveram acesso ao estudo teórico e metodológico acerca do letramento literário destinado aos anos iniciais da Educação Básica, notadamente, à alfabetização; e, tampouco acesso a leituras literárias em sua formação de leitor, consequentemente sua história de leitura é insuficiente para provocar o entusiasmo e o incentivo de novos leitores, pois como diz Cosson (2010) o modo de ler e analisar um texto literário precisa ser aprendido tal como se aprende outras práticas e conteúdos. Para o autor, “o espaço da literatura como texto na sala de aula trata dessa necessidade de aprendizagem que demanda tanto o contato permanente com o texto literário quanto a mediação do professor na formação do leitor"' (COSSON, 2010, p. 61). 
Nesse contexto, o professor é o protagonista na mediação da aquisição da leitura e da escrita, e, em se tratando da leitura dos livros de imagem, ele é quem ensina a compreender o texto quando formula, cria e planeja estratégias interessantes para a construção dos conhecimentos éticos e estéticos da literatura. Assim, selecionar um bom texto literário (às vezes com a participação dos alunos), adequado aos objetivos da turma/do aluno e preparar o ambiente para ler um livro é fundamental; em seguida, pensar e elaborar alternativas para explorar o texto também são partes necessárias para alcançar bons resultados. Com isso, pretendemos, na sequência, apresentar estratégias de leitura que sugerem possibilidades de ler literatura, alfabetizando e letrando o leitor dos anos iniciais, isto é, ofertamos algumas práticas e experiências que partem de narrativas de imagem, exigindo a voz ativa do leitor e incitando-o a relacionar elementos simultâneos da visualidade para contar/dizer o que lhe é aguçado, tanto pelo livro, quanto pela mediação do professor.

Duas obras de uma mesma autora foram nossas escolhas. De inegável qualidade, as obras Cabra-Cega (1998) e Truks (1991), da escritora e ilustradora Eva Furnari, exigem níveis de complexidade de leituras diferentes. Ambas mostram o estilo reconhecido da autora e abarcam em tom "brincalhão" as travessuras da infância, aliadas à fantasia e imaginação de poderes mágicos ou atribuídas tão somente ao universo lúdico das brincadeiras infantis. Por fim, nosso propósito considera o desenvolvimento da sensibilidade e experiência estética a partir do contato com obras visuais durante o ciclo da alfabetização, sob o princípio de que estamos favorecendo o letramento literário em correspondência imediata com a aquisição da leitura e da escrita da criança.

\section{2. "Ah, as palavras visuais"3}

A partir das discussões e dos apontamentos expostos em seções anteriores, passamos a descrever e sugerir as estratégias de leitura que servem de apoio à leitura dos livros Cabra-Cega (1998) e Truks (1991), citados recentemente. As propostas são fundamentadas nos estudos desenvolvidos por Isabel Solé (1998), a qual afirma que o ensino das estratégias de leitura auxilia o leitor a aplicar seu conhecimento prévio, a

\footnotetext{
${ }^{3}$ Elias José, 1996, s/p.
} 
realizar inferências para interpretar o texto e a identificar e esclarecer o que não compreende. A estudiosa também aponta que o trabalho com a leitura em sala de aula é dividido em três etapas: o antes, o durante e o depois da leitura.

Segundo a autora, constituem as estratégias de compreensão leitora para antes da leitura: antecipação do tema ou ideia principal a partir de elementos paratextuais, como título, subtítulo, o exame de imagens, de saliências gráficas; levantamento do conhecimento prévio sobre o assunto; expectativas em função do suporte; expectativas em função da formatação do gênero e expectativas em função do autor ou instituição responsável pela publicação.

As atividades durante a leitura contribuem para a confirmação, rejeição ou retificação das antecipações ou expectativas criadas antes da leitura; localização ou construção do tema ou da ideia principal; esclarecimentos de palavras desconhecidas a partir da inferência ou de consultas ao dicionário; formulação de conclusões implícitas no texto, com base em outras leituras, experiências de vida, crenças, valores; formulação de hipóteses a respeito da sequência do enredo; identificação de palavras-chave; busca de informações complementares; construção do sentido global do texto; identificação das pistas que mostram a posição do autor; relação de novas informações somadas ao conhecimento prévio e identificação de referências a outros textos.

Solé (1998) conclui, afirmando que as atividades para depois da leitura auxiliam na construção da síntese semântica do texto; utilização do registro escrito para melhor compreensão; troca de impressões a respeito do texto lido; relação de informações para tirar conclusões; avaliação das informações ou opiniões emitidas no texto e avaliação crítica do texto.

Dessa forma, as estratégias para antes, durante e depois da leitura pretendem desenvolver um repertório de situações para que a criança possa, "enquanto lê, ativar, explicitamente, por meio [dessas] estratégias, o conhecimento prévio, estimulando-a a fazer conexões entre suas experiências, seu conhecimento sobre o mundo e o texto" (GIROTTO; SOUZA, 2010, p. 55). Para esse trabalho, indicamos que o professor escolha a melhor forma de planejar seu fazer pedagógico, podendo ser organizado em forma de oficinas de leituras, sequencias didáticas e até mesmo desenvolvido dentro de um projeto didático que possa contemplar o conhecimento da autora Eva Furnari e sua obra ou 
abarcar a diversidade dos livros de imagens em seus diferentes estilos e estéticas dos mais diversos ilustradores brasileiros ou não. Então, vamos às obras!

\subsection{Cabra-Cega (1998) - antes, durante e depois da leitura}

Para iniciar a apreciação literária, é preciso seguir alguns passos importantes, que podem começar pela exploração visual da capa ou partir para outras partes do livro. Nesse caso, optamos por examinar os paratextos que acompanham a obra Cabra-Cega (1998), lembrando que esse livro é composto por várias historietas que têm por motivo as brincadeiras na infância, ou seja, não temos uma única narrativa, mas sim várias pequenas histórias, as quais podem ser analisadas e trabalhadas separadamente na sala de aula. Assim, chamamos a atenção do professor para que observe se este é o primeiro contato ou não das crianças com esse livro ou com livros de imagens, pois neste caso é necessário ir com mais calma.

Então, já na capa, os alunos encontrarão informações que despertarão muitas curiosidades, que permitirão que eles recordem algumas situações que já vivenciaram. Portanto, apresente o título, subtítulo e as imagens da capa. Levante as informações sobre os conhecimentos prévios dos seus alunos, eles certamente possuem muitos!

$1^{\circ}$ Passo - A história começou: quem são mesmo essas crianças?

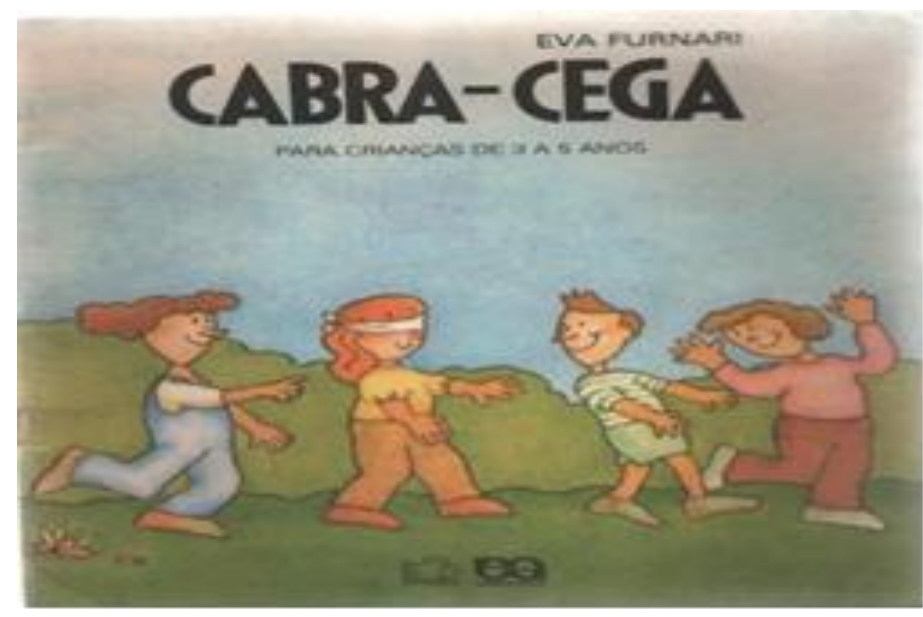

Fig. 4- Capa do livro Cabra-Cega Fonte: Furnari (1998) 
Inicie a atividade mostrando a imagem (Fig. 4), fazendo as seguintes perguntas:

$\checkmark$ Vocês conhecem essas personagens?

$\checkmark$ Qual será a idade delas?

$\checkmark$ Elas têm nomes? Hum, como poderíamos chamá-las?

$\checkmark \quad$ Elas são amigas ou parentes?

$\checkmark$ Como estão vestidas?

$\checkmark$ Que lugar é esse onde elas estão?

$\checkmark$ Onde elas estão indo?

$\checkmark$ O que estão fazendo?

$\checkmark$ Será que estão brincando?

$\checkmark$ Será que essa menina com os olhos vendados tem dificuldade para enxergar?

$2^{\circ}$ Passo - Dona Ática? Seus alunos precisam saber o que é uma editora!

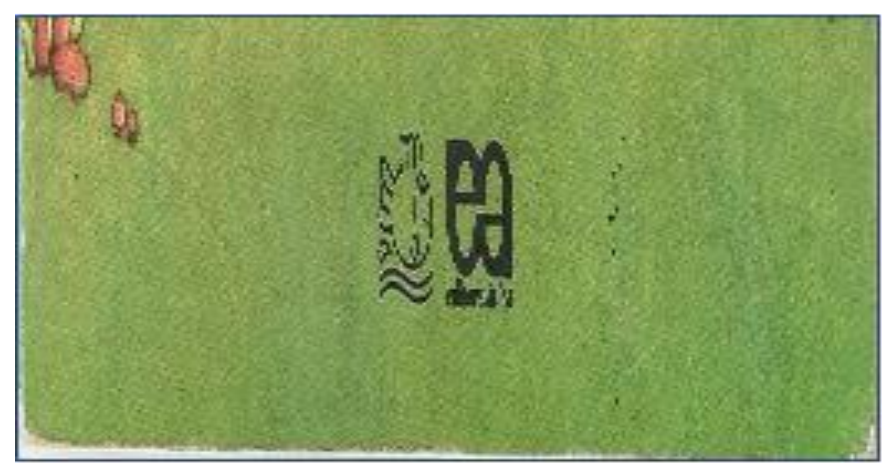

Fig. 5 - Parte inferior da capa da obra Cabra-Cega

Fonte: Furnari (1998)

$\checkmark$ Quem é essa tal de editora Ática?

$\checkmark$ Vocês conhecem?

$\checkmark$ Mas isso é nome de gente ou de um lugar?

$\checkmark \quad$ E por que esse nome está bem pequeno e bem no finalzinho da capa?

$\checkmark$ Tem alguma coisa ao lado do nome?

$\checkmark \quad$ O que é isso?

$\checkmark$ Hum, será que ele é o filho dessa dona Ática?

$\checkmark \quad$ E onde o peixe vive?

$\checkmark$ Mas se peixe vive no mar, o que ele está fazendo aí nessa grama?

$\checkmark$ Então, esse peixe é uma coleção? 
$\checkmark$ Mas será que essa tal de coleção também faz parte da história?

$\checkmark$ Então, dona Ática é uma editora e ela quem criou essa coleção?

$\checkmark$ Mas vocês sabem o que uma editora faz?

$3^{\circ}$ Passo - É hora das inferências: quem é mesmo Cabra-Cega?

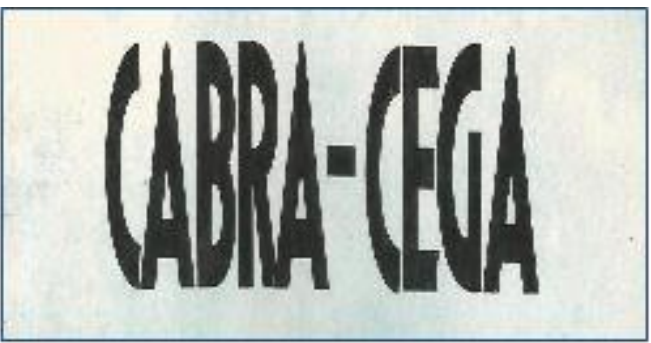

Fig. 6 - Título do livro Fonte: Furnari (1998)

Levante hipóteses e promova questionamentos sobre possíveis histórias ou temas do livro. Investigue se as crianças conhecem essa brincadeira e as instigue a brincar!

$\checkmark$ Vocês conhecem alguma Cabra-Cega?

$\checkmark$ É animal?

$\checkmark$ É pessoa?

$\checkmark$ É brincadeira?

$\checkmark$ Mas dá pra trazer uma cabra cega agora para a sala de aula?

$\checkmark$ É a pessoa Cabra-Cega, nós podemos convidá-la?

$\checkmark$ E a brincadeira, nós conseguiremos brincar?

$\checkmark$ Então, como brincamos disso?

$\checkmark$ Vamos brincar, ou vamos ler?

$\checkmark$ Ótima ideia: vamos fazer as duas coisas ao mesmo tempo!

Na continuação das atividades, após a primeira etapa de reconhecimento do livro (ANTES DA LEITURA), passamos a descrever atividades que podem ser trabalhadas com o intuito de aprofundar mais a leitura do texto literário (DURANTE A LEITURA). Entretanto, recomendamos que o professor aproveite o momento para apresentar outros títulos da autora ou mesmo da editora; inclusive, comente sobre o Prêmio Melhor para criança, 
Livro sem texto, da Fundação Nacional do Livro Infantil e Juvenil (FNLIJ), pela qual o livro foi premiado.

$1^{\circ}$ atividade: Brincando com a literatura!

Comece pelo sorteio para que um aluno seja a Cabra-Cega. Em seguida distribua as imagens do texto lúdico entre as demais crianças que farão parte da brincadeira. Instruções: O aluno que estará vendado deverá procurar os demais, e na medida em que encontrar, deverá pegar a figura que está com o colega e colocar no quadro ou em outro local que esteja reservado para a brincadeira. Ao fim dessa primeira atividade, a CabraCega precisa dar nome à história e contá-la de acordo com a sua imaginação, por isso as imagens devem ser agrupadas seguindo a ordem em que forem encontradas durante a brincadeira, como no exemplo que segue:

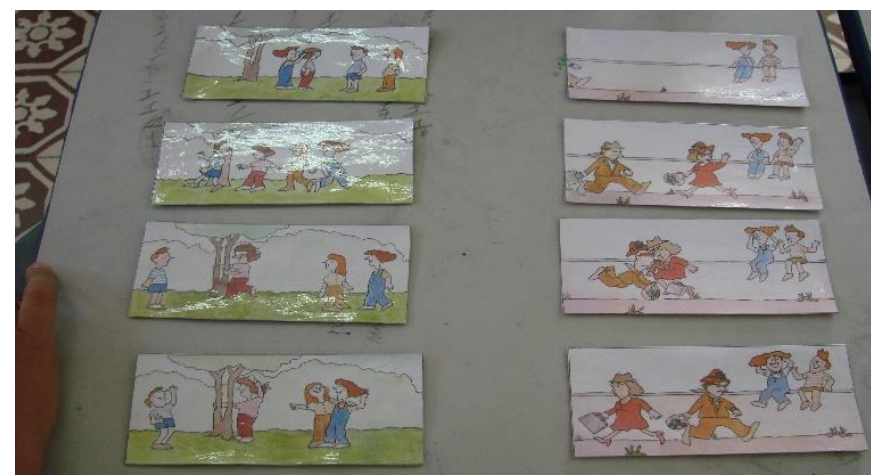

Fig. 7 - Duas historietas do livro Cabra-Cega Fonte: Foto de arquivo pessoal, 2015.

$2^{\circ}$ atividade: Criando e recriando!

No segundo momento, organize um círculo e explique a atividade para os alunos. É importante que nessa tarefa coletiva, eles compreendam que todas as decisões devem ser compartilhadas. Depois, organize a turma em grupos e entregue uma cópia de cada historieta que foi encontrada durante a brincadeira anterior. Instruções: Os grupos terão a missão de criar novas histórias a partir da sequência em que as imagens forem organizadas por eles. Concluída essa primeira etapa de organização, os grupos serão convidados a recontar a história usando a imaginação e, dessa forma, a cada leitura diferente, uma nova história estará sendo criada. 
$3^{\circ}$ atividade: Contando como a autora contou!

Professor, essa missão dedicamos a você: portanto, sugerimos que mostre aos alunos como estão as sequências das imagens no livro que foi escolhido (conforme Fig. 8), e dessa vez, é a maneira como você imagina essa história que todos nós gostaríamos de ouvir. Deleite-se, crie e recrie quantas vezes achar necessário; o mundo das brincadeiras e da literatura é infinito!

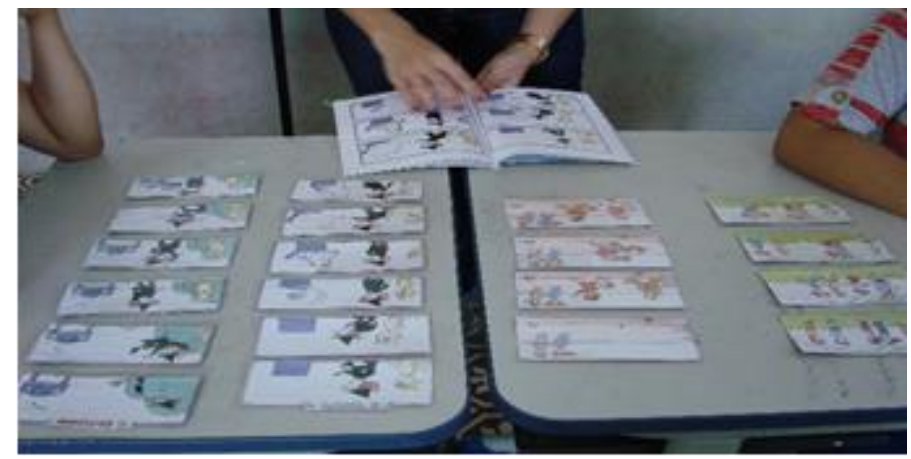

Fig. 8 - Atividade com os livros Cabra Cega e A bruxinha Atrapalhada

Fonte: Foto de arquivo pessoal, 2015

Finalizando mais uma etapa das estratégias de leitura, indicadas por Isabel Solé (1998), chegamos ao último passo (DEPOIS DA LEITURA). As atividades elencadas até aqui não são inéditas, mas permitem alternar outros modos de promover a brincadeira e a leitura do livro Cabra-cega (1998), uma vez que foram vivenciadas por professores dos anos iniciais ${ }^{4}$, e pouco conhecidas por eles, conforme podemos ver nas fotos do nosso arquivo pessoal (Fig. 7 e 8). Portanto, é hora de juntar todas as informações. Lembram-se de tudo que lemos e brincamos?

Vocês entenderam... Que Cabra-cega, não era nem gente, nem animal, nem um lugar? Ah, então ela era mesmo uma brincadeira, né?

Vocês entenderam... Que Dona Ática, na verdade não é dona, é editora, e o que ela faz mesmo?

\footnotetext{
${ }^{4}$ Em 2015, desenvolvemos o projeto (PROLICEN) Literatura nas aulas de língua portuguesa? Onde está o texto literário no ensino fundamental? Em duas escolas da rede pública municipal; uma localizada no município de Pilar/PB e outra em Bayeux/PB. Além da pesquisa, realizamos oficinas de leitura de literatura infantil e juvenil com os professores.
} 
Vocês entenderam... Que o peixe não é filho da editora Ática, mas é símbolo da coleção dela. Hum, acho que ele continua sendo filho.

Vocês entenderam... Que aquelas crianças não são irmãs? Êpa, quem disse isso? Elas são o que vocês disseram que são.

Vocês precisam entender... Olha essa capa aqui, tem o nome de outra pessoa: Quem é Eva Furnari? Nossa, acho que nos esquecemos dela, então vamos entender...

Professor, se você ainda não expandiu a discussão para conhecer um pouco mais a escritora e ilustradora Eva Furnari, então, vamos fazer isso agora. Essas informações estão além da leitura, portanto, pesquise mais dados sobre a autora do livro que possam agregar conhecimentos aos seus alunos; além disso, apresente outros títulos que ela escreveu; seus alunos certamente se sentirão motivados a conhecê-los para continuar brincando através da leitura. Lembre-se: você é um mediador entre o mundo da literatura e o universo infantil dos seus alunos, é responsável por aguçar, incentivar e ensinar a compreensão de mundos e de possíveis leituras que a criança pode realizar nos primeiros passos da alfabetização.

\subsection{Truks (1991) - Antes, durante e depois da leitura}

Na primeira estratégia de leitura, você ensinou para os seus alunos como a capa do livro traz elementos importantes para a compreensão da leitura. Sendo assim, é hora de verificar se seus alunos recordam onde estão localizados o título, o nome da autora e da editora, trazendo para a sala de aula, além do livro sugerido, uma caixa grande (decorada). Dentro da caixa coloque um chapéu de bruxinha, uma varinha de condão, uma boneca, um leão, uma cobra, um dinossauro e duas borboletas; se não encontrar esses objetos prontos, recomendamos que os confeccione. O objetivo é oferecer estímulos para a criação de novas histórias, estruturando enredos e descrevendo personagens e cenários, bem como enfatizar expressões e ações decorrentes da leitura sensorial das visualidades que o livro de imagens Truks (1991), de Eva Furnari, proporciona. Assim, vamos aos passos que promovem a leitura integral do livro aqui sugerido. 


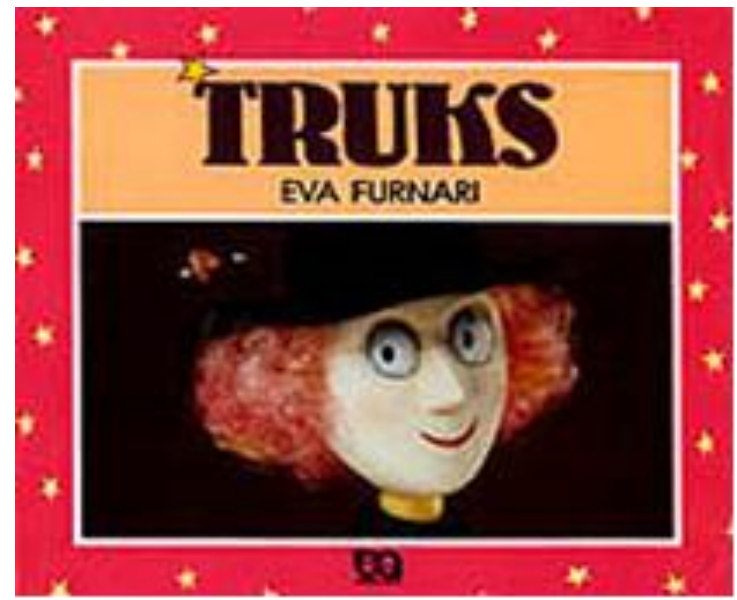

Fig. 9 - Capa do livro Truks Fonte: Eva Furnari (1996)

Nesse primeiro contato com o livro é importante que, a cada resposta correta, seus alunos tenham o direito de retirar um item da caixa que você levou para a sala de aula, pois serão utilizados em atividade posterior.

Qual é o título da história?

$\checkmark$ Mas o que é Truks?

$\checkmark$ Quem faz esses Truks?

Quem criou essa história?

E qual foi a editora que a publicou?

$\checkmark$ Essa pessoa que está na capa, é ela que se chama Truks?

$\checkmark$ Como ela se chama?

$\checkmark$ E o que ela faz?

Os questionamentos auxiliam na descrição da cena e da personagem em correlação com o título, assim a exploração da capa e a imagem da bruxinha constroem os possíveis sentidos da história a ser desvelada na próxima atividade (DURANTE A LEITURA). Entretanto, lembramos que se seus alunos tiverem acertado todas as perguntas, certamente cada um deles já deve ter um objeto que estava dentro da caixa. Então, podemos partir para o próximo passo da leitura prévia. 
$2^{\circ}$ passo - Dando nome aos personagens

Continue com as perguntas, destacando os objetos que estão na sala de aula, em posse dos alunos.

$\checkmark$ Vocês conhecem esses objetos?

$\checkmark$ Que tipo de chapéu é esse?

$\checkmark$ E essa varinha aqui, o que será que ela faz?

$\checkmark$ Uma cobra, um dinossauro, um leão e borboletas: mas que bicharada é essa? De onde será que eles surgiram?

$\checkmark$ Essa boneca? Será que ela se parece com alguém?

Finalize essa etapa, instigando seus alunos: E se eu dissesse para vocês que essa boneca e esses animais fazem parte de uma história que não está muito distante de nós. Sabe onde? Nesse livro que está em minhas mãos. E aí? Estão curiosos para conhecê-los? Então vamos lá!

$\mathrm{Na}$ sequência, apresente as estratégias (DURANTE A LEITURA) que vão descortinar a leitura visual da obra Truks (1991), lembrando que esse livro de imagens propõe uma narrativa integral, ou seja, é preciso ler todas as páginas para obter a história completa (início, meio e fim), diferentemente da proposta do livro Cabra-cega (1998), em que cada página ou páginas duplas continham pequenas historietas. Nesse sentido, é possível destacar a complexidade de uma narrativa para outra, já que Truks (1991) requer mais de seu leitor.

Atividade: Brincando com a literatura!

Chegamos ao momento da leitura compartilhada, então, solicite que seus alunos se sentem em círculo e comecem a folhear as páginas do livro ou, então, apresente em slides ou Power point a obra para que eles possam contar/inventar a história como a percebem e compreendem numa primeira leitura, já que podem não conhecer a obra e até agora foram provocados a inferir possíveis enredos e personagens. É importante ressaltar que, para essa atividade, deve-se folhear o livro ou passar os slides pausadamente, a fim de que os alunos possam apreciar, pensar e retirar o máximo de 
informações e imaginação para sua história. Também é significativo que solicite explicações das crianças, de como elas conseguiram saber/descobrir o que vai acontecendo nas cenas, assim elas consolidam conhecimentos e conceitos a respeito da narrativa, da compreensão e da visão de mundo que aos poucos o texto visual vai promovendo.

Os exemplos que seguem, descrevem e ilustram como essa atividade pode ser realizada com a mediação do professor em sala de aula. Para isso, selecionamos imagens que evidenciam o problema da bruxinha, que se dá por realizar truks errados com sua varinha de condão. Nesse momento, é fundamental que o professor deixe seus alunos negociarem os sentidos do texto; certamente, as perguntas e as surpresas de cada página vão ocasionar inferências que serão acordadas entre eles, bem como serão renegociadas e atualizadas a cada "virar" de página (nova página/imagem).

Fig. 10 - O que aconteceu?

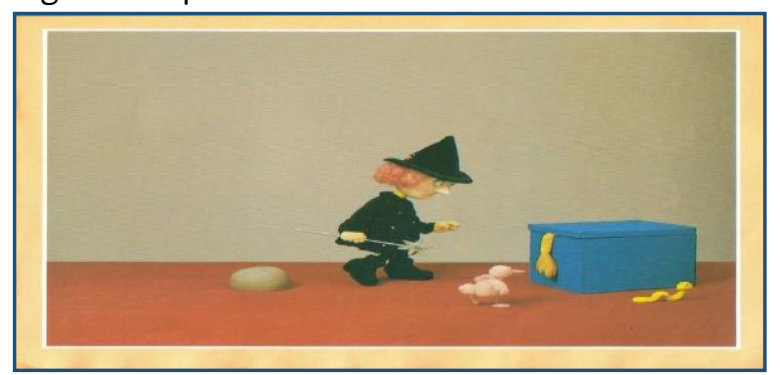

Fonte: Furnari (1991, p. 9)
Fig. $11-\mathrm{Ai}$, que susto!

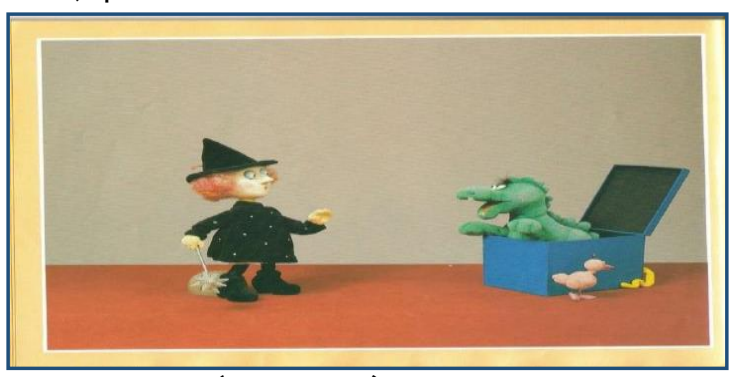

Fonte: Furnari (1991, p. 10)
Fig. 12 - Ops!

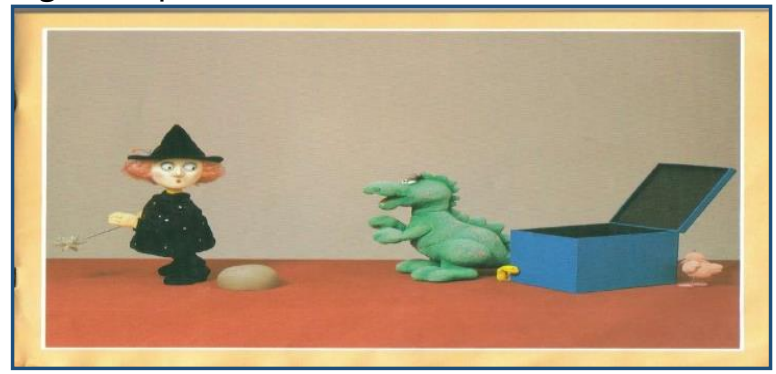

Fonte: Furnari (1991, p. 11)
Fig. 13 - Alguma coisa deu errado!

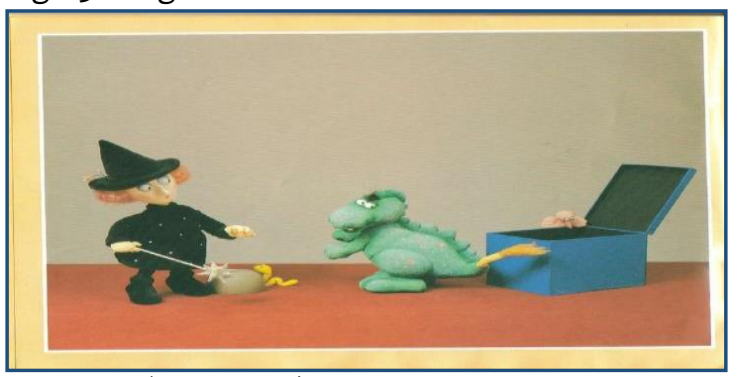

Fonte: Furnari (1991, p. 12) 
Fig. 14 - Vamos pensar!

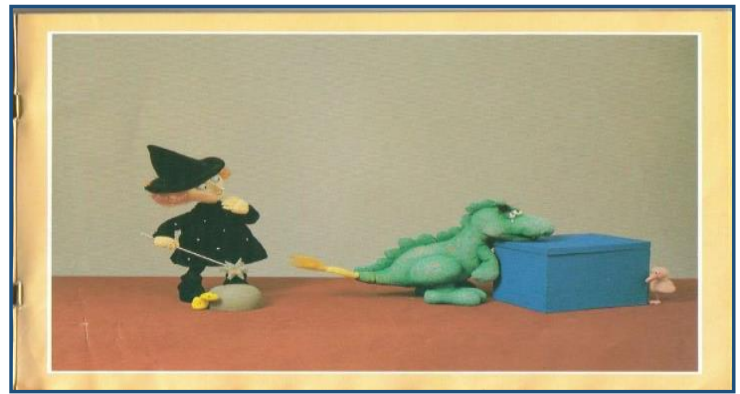

Fonte: Furnari (1991, p. 13)
Fig. 15 - Oitavo truk

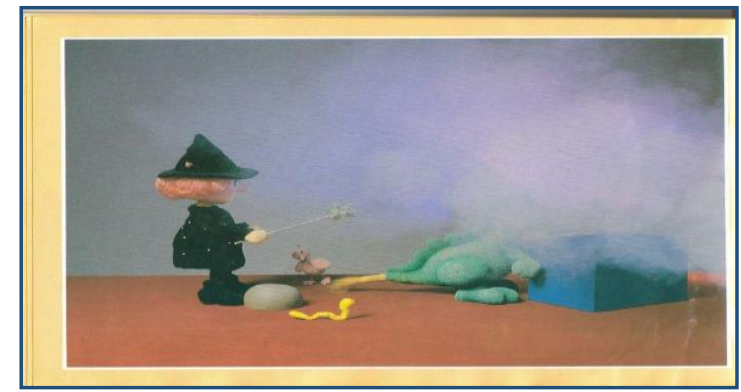

Fonte: Furnari (1991, p. 14)

Durante a mediação da leitura, é necessário que o professor apenas promova questionamentos, deixando os alunos mais livres para articularem e organizarem seus pensamentos. Nesta parte da leitura é fundamental que se observe e avalie os conhecimentos linguísticos e textuais desenvolvidos e incorporados pelos alunos a partir de alguns critérios, como: "levam em consideração as evidências textuais; pensam sobre o que sabem acerca do texto; usam as dicas do texto e seus conhecimentos prévios para responder as questões" (GIROTTO, SOUZA, ..., p. 79). Ainda, poderíamos verificar a utilização de conectores para interligar partes da história e se os mesmos colaboram para o tempo na narrativa, além da percepção do espaço; enfim, como dizem Curto, Morillo e Teixidó (2000, p. 128):

Ao recompor um texto, [as crianças] não se limitam a imitar: trazem suas próprias ideias acerca de como se constrói o texto e sobre o conteúdo. Daí surge o debate e a aprendizagem compartilhada: sobre a estrutura do conto ou texto, o esquema narrativo, a lógica do texto, a inserção de frases ou elementos característicos. (CURTO, MORILLO,TEIXIDÓ, 2000, p. 128)

Encerrando essa estratégia com a valorização da aquisição do código escrito, sugerimos que retome a obra Truks (1991), de Eva Furnari, e registre a história, criando uma narrativa coletiva, em que o professor será o escriba. Finalmente, passamos à última etapa das estratégias apresentadas por Isabel Solé (1998) - DEPOIS DA LEITURA.

A primeira atividade consiste na solicitação de um reconto sucinto da história Truks. Nesse momento será possível verificar que automaticamente as crianças fazem uma seleção, em que os fatos mais importantes serão lembrados e os secundários serão 
deixados de lado. Segundo Isabel Solé (1998), esse é um processo comum que ocorre durante o resumo. Posteriormente, para finalizar a leitura da obra selecionada, propomos a última atividade.

Atividade: E se eu te perguntar, você saberá me responder?

Com base nas informações que seus alunos forneceram para produzir o resumo, selecione alguns elementos que não estavam explícitos nas imagens, e que nesse momento, farão com que, mais uma vez, eles utilizem a imaginação. Algumas das perguntas possíveis, listamos abaixo:

$\checkmark$ Como eram os pais da bruxinha?

$\checkmark$ Sabemos que a bruxinha fez aniversário, mas qual é mesmo sua idade?

$\checkmark$ Por que o livro se chama Truks?

$\checkmark$ Quais foram os truks que a bruxinha fez?

$\checkmark$ Mas todos deram certo?

$\checkmark$ Quais não deram?

Concluímos a elaboração dessas Estratégias de Leitura reforçando que as atividades sugeridas são apenas algumas entre as múltiplas possibilidades que os livros de imagem podem suscitar e provocar para serem trabalhados em sala de aula. Reiteramos que atividades propostas para ANTES, DURANTE E DEPOIS da leitura devem ser orientadas e mediadas pelo professor, pois segundo Isabel Solé (1998), são estratégias utilizadas como ferramenta para o desenvolvimento da leitura proficiente.

\section{Últimas palavras}

Ao longo desse artigo, buscamos mostrar a importância da presença da literatura infantil no ciclo da alfabetização. Situamos com exemplos e experiências o lugar do livro de imagens como uma opção viável para construir e elaborar os processos de ensinoaprendizagem da leitura e da escrita nos anos iniciais. Tudo isso, porque acreditamos que a imagem permite a leitura e a interação com um universo variado de enredos, personagens, cenários, texturas, cores, sensações etc., que podem suscitar na criança a 
construção de significados mais interessantes, que preenchem melhor seus questionamentos e curiosidades a respeito de si e do mundo, além de promover o prazer estético.

Além disso, entendemos que esse é um momento privilegiado para dialogar com essas obras, uma vez que as crianças estão rodeadas e imersas em imagens e sons midiáticos, bem como de cenas, figuras e desenhos por todas as partes, como gibis, outdoors, panfletos e propagandas. Também porque é uma fase propícia para discutir a ilustração, apreciar e ler com mais detalhes, aguçando o olhar, a percepção e o senso estético para a crítica e a leitura, pois como assegura Italo Calvino, ao descrever suas primeiras leituras do código escrito, "seja como for, eu preferia ignorar as linhas escritas e continuar na minha ocupação favorita de fantasiar em cima, das figuras, imaginando a continuação" (1990, p. 109). Isto porque o autor vivenciou antes da aprendizagem da escrita a leitura dos quadrinhos, comics americanos de sua época, em que testemunha sua interlocução com o texto visual da seguinte forma:

Não largava aquelas revistinhas que minha mãe havia começado a comprar e colecionar (...) Passava horas percorrendo os quadrinhos de cada série de um número a outro, contando para mim mesmo mentalmente as histórias cujas cenas interpretava cada vez de maneira diferente, inventando variantes, fundindo episódios isolados em uma história mais ampla, descobrindo, isolando e coordenando as constantes de cada série, contaminando uma série com outra, imaginado novas séries em que personagens secundários se tornavam protagonistas.

Quando aprendi a ler, a vantagem que me adveio foi mínima. (CALVINO, 1991, p. 109)

Em contato com livros de imagens, as crianças, assim como Italo Calvino, têm a oportunidade de descoberta de novos mundos, de fusão e diálogos entre vivências a serem reelaboradas a cada nova figura, a cada nova história. Nesse sentido, os livros de Eva Furnari são alguns dos exemplos que podem ser usados em sala de aula, mas são inúmeros os ilustradores e autores que trabalham cuidadosamente a palavra/imagem em suas obras; e, prosperamente, a literatura infantil nacional e estrangeira nos oferece um conjunto de obras que podem favorecer práticas para o letramento literário e a alfabetização. 


\section{Referências}

BRITO, Rosa Suzana Alves de. Literatura infantil no processo de aquisição da leitura e da escrita. 2013. 143 f. Monografia (Graduação em Pedagogia) - UPB, Mamanguape (PB), 2013. Disponível em: <http://www.ufpb.br/geef/contents/documentos/tcc-literaturainfantil-no-processo-de-aquisicao-da-leitura-e-da-escrita-1.pdf>. Acesso em: 16 de fevereiro de 2017.

CALVINO, Italo. Seis propostas para o próximo milênio. São Paulo: Companhia das Letras, 1991.

CAMARGO, Luís. Ilustração do livro infantil. Belo Horizonte, MG: Lê, 1995.

COSSON, Rildo. O espaço da literatura na sala de aula In: PAIVA, Aparecida; MACIEL, Francisca; COSSON, Rildo (Coord.). Literatura: ensino fundamental. Brasília: Ministério da Educação, Secretaria da Educação Básica, 2010. (Coleção Explorando o ensino, v. 20).

CURTO, Luís M.; MORILLO, Maribel; TEIXIDÓ, Manuel M. Escrever e ler: materiais e recursos para a sala de aula. Porto Alegre: Artmed, 2000.

FERREIRO, Emília; TEBEROSKI, Ana. A psicogênese da língua escrita. Porto Alegre: Artmed, 2011.

FOUCAMBERT, Jean. A criança, o professor e a leitura. Porto Alegre: Artes Médicas, 1998.

FURNARI, Eva. A bruxinha atrapalhada. São Paulo: Global, 2004.

FURNARI, Eva. Cabra - Cega. São Paulo: Ática, 1998.

FURNARI, Eva. Truks. São Paulo: Ática, 1991.

GIROTTO, Cyntia G. S.; SOUZA, Renata Junqueira. Estratégias de leitura: para ensinar alunos a compreender o que leem In: SOUZA, Renata J. Et al. Ler e compreender: estratégias de leitura. Campinas (SP): Mercado de Letras, 2010.

HUNT, Peter. Crítica, teoria e literatura infantil. Trad. Cid Knipel. São Paulo: Cosac Naify, 2010.

JOSÉ, Elias. O jogo das palavras mágicas. Il. Nelson Cruz. São Paulo: Paulinas, 1996. (Coleção Cavalo Marinho. Série Com-verso).

NOVAK, B. J. O livro sem figuras. Trad. Índigo. Rio de Janeiro: Intrínseca, 2015.

PAIVA, Ana; RAMOS, Flávia. O não-verbal no livro literário para criança In: GIROTTO, Cyntia G. S; SOUZA, Renata Junqueira (Org.). Literatura e educação infantil: livros, imagens e práticas de leitura. Vol. 1. Campinas, SP: Mercado de Letras, 2016. (Série Literatura, Leitura, e Educação infantil) 
RAMOS, Graça. A imagem nos livros infantis: caminhos para ler o texto visual. Belo Horizonte: Autêntica, 2013.

SARAIVA, Juracy A. (Org.). Literatura e alfabetização: do plano do choro ao plano da ação. Porto Alegre: Artmed, 2001.

SOARES, Magda. Alfabetização e Literatura. Revista educação: Guia da alfabetização. São Paulo: ed. Segmento, n. 2. p. 13-29, 2010.

SOLÉ, Isabel. Estratégias de leitura. Porto alegre: Artes médicas, 1998. 